\title{
Pedagogia e museificação
}

\author{
Denice Barbara Catani
}

“...no reino do pensamento, a
imprudência é um método", (G. Bachelard)

Ao se compreender a leitura como uma aventura de dar sentidos ao que se vê e assim preencher as formas que foram produzidas pelo seu autor, como suposições de sentido, pode parecer razoável falar de educação, ao mesmo tempo em que se fala de Elias Canetti e do primeiro volume de sua autobiografia, exaustivamente comentada pela crítica brasileira por ocasião de sua tradução, em 1987(1).

Pensar a leitura d'A lingua absolvida como leitura fértil para a compreensão do tema da educação é algo que pode servir de alento aos que há muito jâ se fartaram com as produções usuais da pedagogia. Configuração, por excelência, da unicidade de sentido e esforço extremado da tentativa de imposição da forma inequívoca, ordenada e disciplinada, grande parte de seus representantes talvez não visse com prazer o fato de que a figura do professor que mais fala ao autor seja a de Witz, o professor de História. Um homem que “... sempre procurava e jamais encontrava (...) não sabia o que fazer, como viver (...) nem sequer sabia para onde ia, voltava-se ora para este, ora para aquele; só tinha uma certeza, ele queria ser instável, e, por mais que isto me atraísse, pois era dito com suas próprias palavras, por sua boca, me deixava maravilhosamente confuso - mas para onde eu o seguiria?"' (pp. 277-8).

Sem dúvida alguma é o gênio conhecido de Canetti que lhe permite amar também uma alternativa que ele considera diametralmente oposta - a de Karl Beck, o professor de Matemática - com sua maneira "tenaz e disciplinada de ensinar". "Partindo-se de uma área talvez muito pequena, sobre a qual não se tem dúvidas, segue-se com determinação numa única e mesma direção, sem perguntar aonde se quer chegar, renunciando a olhar para a direita ou para a esquerda, avançando para um alvo sem conhecê-lo, e enquanto não se dá um passo em falso e se conserva a correlação entre os passos, nada nos acontece, e chegamos ao desconhecido - pois é a única maneira de conquistar gradualmente o desconhecido"' (p. 273).

Com Witz “... não se caminhava para a frente, mas estava-se ora aqui, ora acolá; não se tinha um alvo em mira, nem sequer uma meta desconhecida; é certo que se recebia muitas informações, mas mais do que ser informado, adquiria-se uma sensibilidade para aquilo que fora descartado ou para o que ainda permanecia oculto. Ele fortalecia sobretudo o gosto pela transformação, quanta coisa existia de que não se tinha idéia, e bastava que a gente ouvisse falar naquilo para que se tornasse aquilo"'(p. 273).

Convém lembrar, não sem certa impaciência, algumas recomendações pedagógicas, em voga há muito tempo: racionalize-se o trabalho do professor, estabeleça objetivos claros, é preciso que se saiba onde se quer chegar, ê preciso levar os alunos a compreender bem e responder claramente às questōes, e tantas outras providências semelhantes. Não é à toa que a pedagogia, ou melhor, os pedagogos se comprazem em dizer isto
DENICE BÁRBARA CATANI é professora-doutora e organizadora do volume Universidade, escola e formação de professores (Editora Brasiliense)

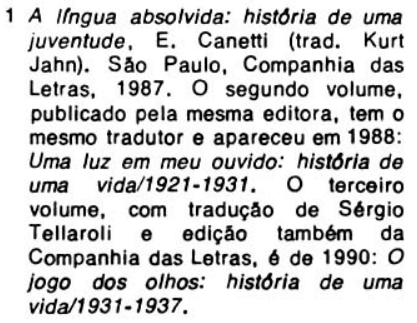
vida/1931-1937.

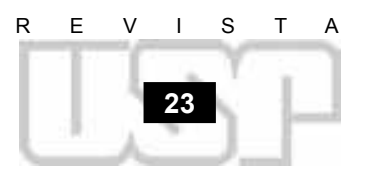


de muitas formas, em muitas linguagens e com várias justificativas: o simples senso comum não "convence" e embora "convencione" não delimita um campo privado de investimentos e produções. Os bons efeitos de tais providências ordenadoras não se ocultam, ao contrário, exibem-se cruelmente na situação de alunos universitários que só pedem clareza e objetividade, sistematizações e uma "visão geral" e que indagam quase solenemente: "qual ê a solução proposta pelo autor?", diante de qualquer texto que não lhes diga o "que fazer", de vez que os textos pedagógicos parecem dever ser feitos para isso, ou de vez que a experiência escolar já lhes mostrou o modo "certo" de compreender. Pequena vingança contra a pedagogia, a novela de Miguel de Unamuno, Amor y pedagogia, ironicamente destrới o sonho da "ciência educativa", contando onde vão dar tais ilusões. Os pedagogos não o lêem (2).

$\mathrm{Na}$ leitura do primeiro volume da autobiografia de Canetti encontram-se elementos que, certamente, permitem pensar a pluralidade de sentidos das experiências de formação, refletir sobre a instituição escolar enquanto lugar de homogeneização dos comportamentos e sobre o espaço aberto para as diferenças nas relações entre os indivfduos. Reconstituir isso, fazendo a rememoração de sua história pessoal, leva o autor a tentar o maior número possível de inclusões: de experiências agradáveis ou desprazerosas, de figuras respeitadas ou não dos professores; e o fazem cruzar seguidamente a história relembrada com a interpretação dos sentidos que atribui a essa história. Sobre a multiplicidade de figuras dos professores, que lhe traz a recordação de sua vida escolar, diz: "... E a primeira diversidade de que se é consciente na vida (...) a alternância dos personagens, um após outro, no mesmo papel, no mesmo lugar e com a mesma intenção, portanto eminentemente comparáveis - tudo isso, em seu efeito conjunto é outra escola, bem diferente da escola formal, uma escola que ensina a diversidade dos seres humanos; se a tomarmos um pouco a sério, resulta a primeira escola em que conscientemente estudamos o homem" (p. 174). Não se pode deixar de atentar para o fato de que ler Canetti, na situação d'A língua absolvida, permite multiplicar as sugestões sobre o tema da educação, mas além disso permite justamente acompanhá-lo cruzando a história do menino - vítima do "método pedagógico" da mãe que lhe ensina alemão ou daquele que deseja exibir seus conhecimentos na escola e por isso é repreendido - com a do adulto que procura o lugar que cada um desses acontecimentos ganhou na constituição de si próprio.

Walter Benjamin faz alusões férteis sobre o trabalho de recuperar a própria história, ao falar de Proust: “... Nem tudo nessa vida é modelar, mas tudo é exemplar..." E prossegue: "o importante para o autor que rememora não é o que ele viveu, mas o teci- 


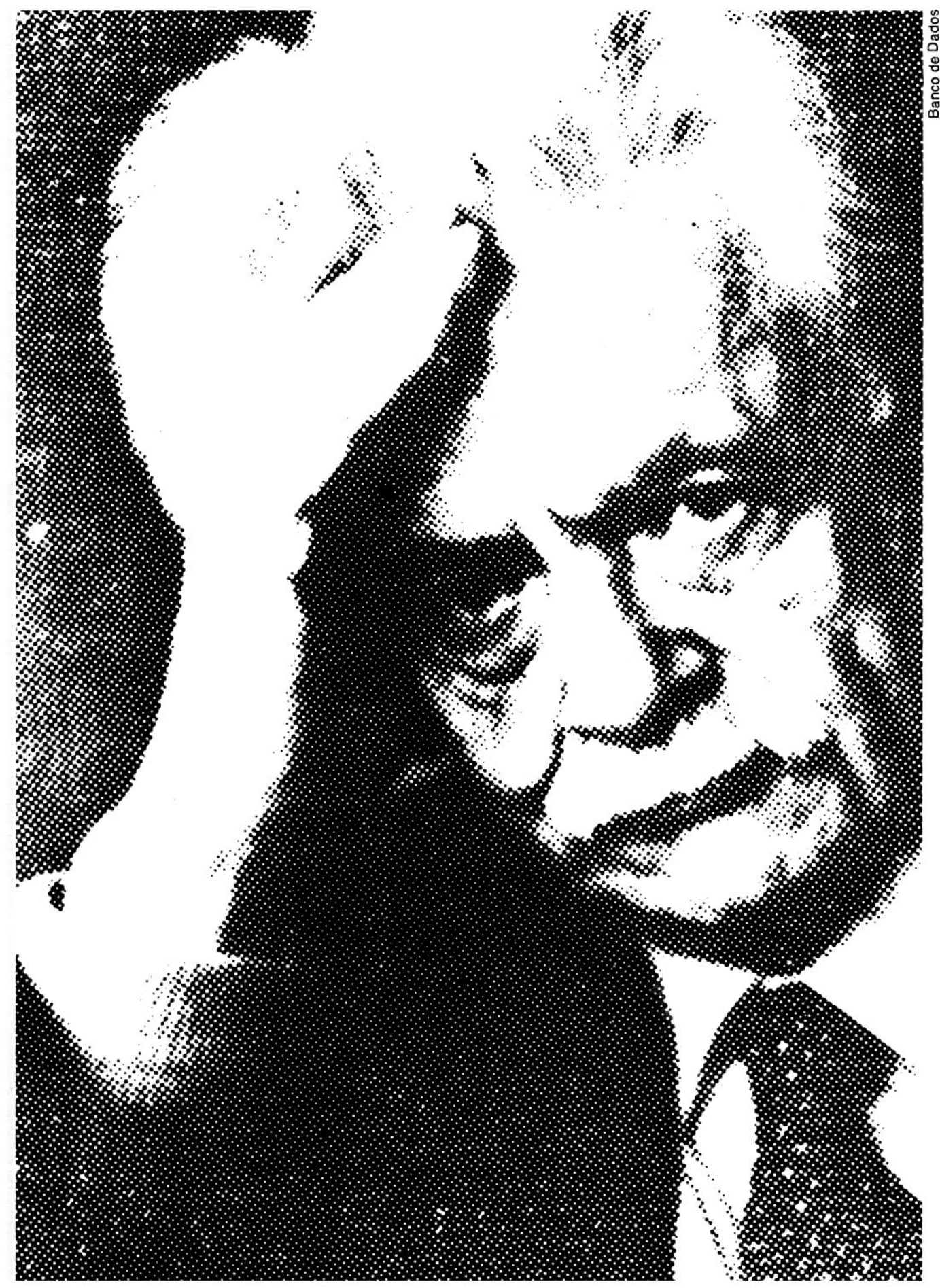

do de sua rememoração, o trabalho de Penélope da reminiscência. Ou seria preferível falar do trabalho de Penélope do esquecimento?(...) Não seria esse trabalho de rememoração espontânea em que a rememoração é a trama e o esquecimento a urdidura, o oposto do trabalho de Penélope, mais que sua cópia? Pois aqui é o dia que desfaz o trabalho da noite"(3). Para o seu trabalho de rememoração e esquecimento Canetti escolhe a via direta da autobiografia e para ele também podem valer as observações de Benjamin: nem tudo modelar, mas certamente exemplar. Pois não é ele que obriga seu texto a falar simultaneamente a trama e a urdidura de sua história? Seu relato afirma e reitera escolhas sem deixar de aludir aos sentidos do que foi recusado, mostrando assim como se faz sua atenção para o mundo. E é talvez, no modo como se constrói essa atenção e

Elias Canetti, nascido em 1905 e autor de $A$ lingua absolvida

\section{Dezembro


se a expressa na rememoração da sua experiência escolar, que se pode melhor encontrar os elementos sugestivos para o tema da educação.

Cabe lembrar aqui, que quando fala sobre o efeito de "museificação" da arte Renato Mezan, retomando Broch, assinala as conseqüências neutralizadoras das medidas de proteção: o arranjo das oùras, seu isolamento do público ou sua classificação como exemplo de estilo ou autor, enfim, as providências que colocam o espectador a salvo “do poder de sedução e inquietação contido na obra". Diz ainda: “... que se tenha tornado necessário ensinar a ver o que mostra um quadro ou uma estátua diz muito sobre esta função de neutralização da arte, já que a melhor maneira de se escudar do sentido de uma produção humana é ignorar a forma pela qual ela se materializa, num estilo determinado e num código expressivo particular"(4). Não deixa de ser curioso observar que alguém, como Canetti, que segundo seus criticos faz a apologia do ouvir (ou de uma cultura auricular), e reserva para a descrição dos anos da maturidade o "jogo dos olhos", seja o mesmo que não se furta a dar-se a ver, exibindo o modo pelo qual constrói e reconstrói a sua própria história.

Mas, caso se volte brevemente o olhar para a pedagogia e suas regras de dotação de sentido único, não caberia perguntar se, a pretexto de "ensinar a ver", não estaria ela própria olvidando o sentido das produções humanas e ocultando suas formas de materialização em estilos e códigos expressivos? Não consiste a pedagogia num conjunto cada vez mais acabado de providências para "ensinar a ver" de uma determinada forma? Tenha-se presente a aludida preferência de Canetti pelo ouvir, que permitiria penetrar o que não se exibe aos olhos; ouvir a "ordem das coisas", pelo menos no duplo sentido de ceder a elas e de descobrir outras classificações que não se impõem pela visão. É de Bachelard que vêm as observações sobre a supremacia do olhar e, segundo ele, "sonhar e ver concordam pouco: quem sonha muito livremente perde o olhar quem desenha excessivamente bem perde os sonhos de profundidade"(5).

Entretanto, para a pedagogia não há sonhos de profundidade, como não há multiplicidade de sentidos para as produções humanas, nem há rumores a se ouvir: tudo deve se dar visivelmente, transparentemente, quase que vitrificadamente. Não se precisa recuar muito no tempo para encontrar os educadores paulistas, do inf́cio da República, a bradarem: "Luz, luz, muita luz!", para que a instrução funcionasse como a chave do progresso nacional. E o sonho da iluminação inspira ainda hoje: textos pedagógicos esclarecem o professor sobre "o que" fazer, guiam os seus passos pelo melhor caminho. E parece que esse foco de luz dos textos pedagógicos deve se dirigir a um único ponto, a um único sentido, destinado a fazer desaparecer a diversidade ou pelo menos unificá-la, convergindo para a interpretação certa, adequada, como se gosta de dizer. Mas quantas ocultações de sentido é preciso que se faça para chegar à "interpretação correta" e como se ensina alguém a fazer isso? A pedagogia como disciplina e ordenação das regras, ao impor o afastamento da dispersão e pôr-se a serviço da interpretação única, abstrai a história, exclui o que desconcerta e é inesperado. Garantia de tranqüilidade, porque providência para a exclusão do erro, a pedagogia agarrada à ilusão dos controles justifica-se elaborando o discurso do "museu": classifica e organiza, isola e dirige o olhar, alem de imprimir os folhetos que ensinam a percorrer os conhecimentos selecionados como dignos, destituídos do seu "poder de sedução e inquietação"(6).

Seria preciso uma leitura da autobiografia de Canetti para dar-se conta desses riscos, tantas vezes já apontados, que marcam a pedagogia? Sim, se se quer multiplicar as questões para pensar o tema da educação ou se se quer apontar para a possibilidade de entrever essa utilização de textos "não-pedagógicos" para tratar as questões. A lingua absolvida apresenta-se como oportunidade privilegiada para interrogações acerca da formação intelectual e hipóteses para a compreensão das relações que se mantêm com a leitura e com os conhecimentos "legítimos" divulgados pela escola. Repõe assim questões com que se defrontam usualmente aqueles que lidam com educação e que, ao falar do tema, acabam por permanecer na mesma situação apontada por $P$. Bourdieu para o of́cio do sociólogo e suas dificuldades em comunicar o resultado de seus trabalhos, situados sempre entre dois papéis: "de um lado, o de desmancha-prazeres e do outro, o de cúmplice da utopia"(7). No limite do exerććcio desse segundo papel, cabe ainda perguntar: por que não Witz (o professor de História), contra a prudência pedagógica, que faz uma espécie de trabalho diurno de Penélope sobre a imaginação dos alunos? 